\title{
Studi Fenomenologi Perilaku Homoseksual Di Kota Semarang
}

\author{
Sri Puji Lestari ${ }^{1}$, Indah Wulaningsih ${ }^{2}$, Lailatul Fitriyah ${ }^{3}$ \\ 1,2,3 STIKes Karya Husada Semarang \\ J1. Kompol R. Soekanto No. 46 Sambiroto, Semarang \\ E-mail:Lestari.budiyono@gmail.com
}

\begin{abstract}
Abstrak
Homoseksual merupakan masalah global dan modern sekarang ini, gaya hidup atau lifestyle merupakan hal yang sangat penting dan kerap menjadi ajang untuk menunjukkan identitas diri. Saat ini cukup banyak komunitas dan organisasi homoseksual baik formal maupun informal. Tujuan penelitian ini adalah mendeskripsikan fenomena perilaku homoseksual di Kota Semarang.Desain penelitian yang digunakan adalah desain penelitian fenomenologi kualitatif. Partispisan dalam penelitian ini adalah 4 orang homoseksual yang berada dalam sebuah komunitas homoseksual di kota Semarang. Hasil penelitian menunjukkan partisipan berteman baik dengan siapapapun, partisipan melakukan hubungan seksual dengan berbagai cara, baik oral, bodycontact dan anal. Diharapkan untuk para homoseksual agar dapat berperilaku secara baik dalam perilaku sesksual maupaun perilaku secara umum sesuai kaidah di masyarakat agar kehadirannya dapat diterima dalam lingkungan.
\end{abstract}

\section{Kata Kunci: homoseksual; perilaku}

\section{Phenomenological Study Of Homosexual Behavior In The City Of Semarang}

\begin{abstract}
Homosexuality is a global and modern problem nowadays, lifestyle or lifestyle is very important and is often the place to show identity. Currently there are quite a number of homosexual communities and organizations both formal and informal.The purpose of this study was to describe the phenomenon of homosexual behavior in the city of Semarang. The research design used was a qualitative phenomenological research design. Participation in this study were 4 homosexuals who were in a homosexual community in the city of Semarang.

The results of the study showed that participants were good friends with anyone, partisans of having sexual intercourse in a way, both oral, body contact and anal. It is expected that homosexuals can behave well in sexual behavior or general behavior in accordance with the rules in society so that their presence can be accepted in the environment.
\end{abstract}

Keywords : behavioral, homosexuals

\section{Pendahuluan}

Homoseksual merupakan masalah global dan modern sekarang ini, gaya hidup atau lifestyle merupakan hal yang sangat penting dan kerap menjadi ajang untuk menunjukkan identitas diri. Homoseksual sudah menjadi suatu fenomena yang banyak dibicarakan di dalam masyarakat, baik di berbagai negara maupun di Indonesia. Di Indonesia sendiri homoseksual masih menjadi suatu fenomena seksual yang masih terbilang tabu dan dianggap aneh oleh sebagian 
masyarakat, walaupun di negara-negara barat fenomena ini sudah tidak lagi menjadi suatu fenomena yang dianggap tabu lagi (Spencer, 2010).

Menurut World Health Organization ( WHO) memprediksi jumlah LGBT jauh lebih banyak, yakni tiga juta jiwa pada 2011. Data tahun 2009 populasi gay hanya sekitar 800 ribu jiwa. Mereka berlindung di balik ratusan organisasi masyarakat yang mendukung kecenderungan untuk berhubungan seks sesama jenis. Data 2012 diperkirakan jumlah gay mencapai 3 juta, tahun 2010 diperkirakan 800 ribu.Data Estimasi Kemenkes pada 2012, terdapat 1.095.970 homoseksual baik yang tampak maupun tidak. (Dewi, 2015)

Menurut survey yang dilakukan oleh YPKN tahun 2003, bahwa di Indonesia terdapat 45ribu gay. Populasi gay di Indonesia diperkirakan akan meningkat sebesar 5\% setiap tahunnya. Data Yayasan Mitra Indonesia tahun 2013 menunjukkan bahwa populasi gay sekitar 3 juta orang. Terjadi peningkatan yang signifikan pada tahun 2010 dibandingkan dengan tahun 2013 . Data tahun 2010 sebesar 506 kasus sedangkan tahun 2013 sebesar 3.287 kasus. (Dwilaksono, 2014)

Di Kota Semarang sendiri terdapat 2 komunitas Gay, salah satunya adalah Semarang Gaya Community (SGC). SGC sendiri merupakan sebuah organisasi berbasis komunitas (Gaydan LSL lainnya) yang non-pemerintah dan independen.Di Jawa Tengah jumlah gay berdasarkan data komunitas Gessang pada tahun 2015 sekitar 150.770 orang. Selain itu menurut data Rumah Pelangi Indonesia, jumlah gay tahun 2015 (sampai September) di Kota Semarang hampir 17.245 orang.

Berdasarkan hasil survey pada tanggal 8 April 2017 pukul 21.00 WIB didapatkan data jumlah homoseksual di Semarang mencapai 7.059 orang, yang bertempat di perum korpri Kecamatan Tembalang. Dari wawancara yang didapatkan dari salah satu gay mengatakan bahwa menjadi seorang gay tanpa disadari dan mengatakan dari awal menginjak dewasa sudah tertarik kepada laki-laki,tidak tertarik kepada perempuan.

\section{Tinjauan Teoritis}

Homoseksual berasal dari bahasa yunani yaitu (homoios = sama) dan bahasa latin (sexus $=$ jenis kelamin) merupakan pengertian umum mencakup banyak macam kecenderungan seksual terhadap kelamin yang sama, atau secara lebih halus adalah suatu keterarahan kepada kelamin yang sama (homotropie; tropos = arah, haluan). (Tahmindjiis, 2014) 
Tindakan homoseksual bukan merupakan bagian dari pengaruh kontemporer. gaya hidup orang-orang barat semata merupakan bagian kebutuhan manusia dalam memenuhi orientasi seksualnya yang bersifat alamiah atau natural, yang kemudian menjadi berfungsi dan distrukturkan dalam berbagai lembaga lokal dalam berbagai kebudayaan masyarakat (Adesla, 2009)

Tingkah laku abnormal atau menyimpang adalah tingkah laku yang tidak adekuat, tidak bisa diterima oleh masyarakat pada umumnya, dan tidak sesuai dengan norma sosial yang ada. Seorang individu atau kelompok yang dalam mencapai tujuannya tidak dapat menyesuaikan dengan norma yang berlaku maka disebut deviasi. (Afifudin \& Saebani, 2010).

Adelsla (2009) menjelaskan deviasi Kultural dapat dibagi menjadi tiga, yaitu Deviasi individual. Deviasi ini merupakan gejala personal, pribadi atau individual, sebab yang ditimbulkan oleh ciri-ciri yang unik dari individu itu sendiri. Yang kedua adalah Deviasi Situasional disebabkan oleh pengaruh bermacam-macam kekuatan situasional atau sosial di luar individu atau oleh pengaruh situasi, dimana pribadi yang bersangkutan menjadi bagian integral dari dirinya. Sedangkan Deviasi Sistematik diartikan sebagai orang yang mengalami ketertarikan emosional, romantik, seksual atau rasa sayang terhadap sejenis, sedangkan biseksual merasa nyaman melakukan hubungan seksual dengan kedua jenis kelamin. Secara sosiologis, homoseksual merupakan seseorang yang cenderung mengutamakan orang sejenis kelaminnya sebagai mitra seksual.

Homoseksual disebut homoseksualisme dan keadaan tertarik terhadap orang dari jenis kelamin yang sama disebut homoseksual, beragam pendapat untuk mencoba memahami penyebab homoseksual pada manusia. (Afifudin \& Saebani, 2010). Sunaryo (2011) membagi Homoseksual ke dalam 3 (tiga) kategori, yakni: (1) Golongan yang secara aktif mencari mitra kencan di tempat-tempat tertentu, seperti misalnya bar-bar homoseksual; (2) Golongan pasif, artinya yang menunggu; (3) Golongan situasional yang mungkin bersikap pasif atau melakukan tindakan-tindakan tertentu.

\section{Metode Penelitian}

Metode Penelitian yang digunakan adalah peneltian kualitatif dengan desain fenomenologi yaitu penelitian kualitatif yang berakar pada filosofi dan psikologi, dan berfokus pada pengalaman hidup manusia. Tujuan penelitian kualitatif adalah untuk membuat deskripsi, 
gambaran atau lukisan secara sistematis, faktual dan akurat mengenai fakta-fakta, sifat-sifat serta hubungan antar fenomena yang diselidiki dengan banyak penajaman. Penelitian ini menggunakan strategi studi kasus, dengan maksud mempelajari secara intensif tentang latar belakang penelitian yang akan dilakukan.

Partisipan dalam penelitian ini adalah orang dengan perilaku homoseksual diKota Semarang, dimana jumlah partisipan tidak dibatasi namun dalam pengambilan data peneliti telah mencapai saturasi sampai dengan 4 partisipan. Pengumpulan data dengan metode wawancara mendalam atau indepht interview, juga obervasi dan perekam data menggunakan alat perekam. Setelah semua data terkumpul dilakukan analisa data dengan mengolah data dengan metode Colaizzi dimana transkrip wawancara dibaca ulang, kemudian di cari kata kunci dan menyusun kategori. Selanjutnya dari kategori-kategori disusunlah menjadi satu tema yang bermakna. Untuk menguji kredibilitas data, peneliti menggunakan triangulasi sumber yaitu dari orangtua yang serumah dan pakar Psikologi.

\section{Hasil Penelitian}

\section{Karakteristik Partisipan}

Penelitian ini akan menjabarkan hasil wawancara tiap partisipan yang terhimpun dalam 4 partisipan yang terkait masalah perilaku homoseksual. Berikut karakteristik khusus dari masingmasing partispan.

Tabel 1. Karakteristik Partisipan

\begin{tabular}{llllcl}
\hline No & Kode & Usia & $\begin{array}{c}\text { Pendidikan } \\
\text { Terahir }\end{array}$ & Pekerjaan \\
\hline 1 & P 1 & 21 tahun & SMA & Mahasiswa \\
\hline 2 & P 2 & 20 tahun & SMA & Mahasiswa \\
\hline 3 & P 3 & 37 tahun & S1 & Karyawan \\
\hline 4 & P 4 & 23 tahun & SMA & Mahasiswa \\
\hline
\end{tabular}

Berdasarkan Tabel 1 menunjukkan bahwa partisipan penelitian berumur 21 - 37 tahun. Rerata umur partisipan adalah kelompok dewasa muda. 


\section{Pemahaman partisipan tentang homoseksual}

\section{Bagan 1. Faktor Yang Mempengaruhi PerilakuHomoseksual}

Setahu aku ya homoseksual itu sikap dalam orientasi sek mba.Ada 4 jenis lho. Ada biseksual yang bisa suka cewek atau cowok, ada lesbi, gay sama transgender" (P1)

"Homoseksual masuk orientasi seksual mba. Ini bukanlah sebuah penyakit, kelainan jiwa atau gangguan mental. Bahkan menurut penelitian ya mba oleh American Psikiatrik Association of Phsiciatric (APPA), yakni tidak ada perbedaan kepribadian yang mencolok antara homoseksual dan orang normal pada umumnya". (P2)

"Homoseksual itu adalah ketika seseorang mempuanyai ketertarikan secara romantik atau emosional dan atau seksual terhadap sesama jenis. Jadi bisa salah satu diantaranya itu."(P3)

\section{Bagan 2. Alasan Menjadi Homoseksual}

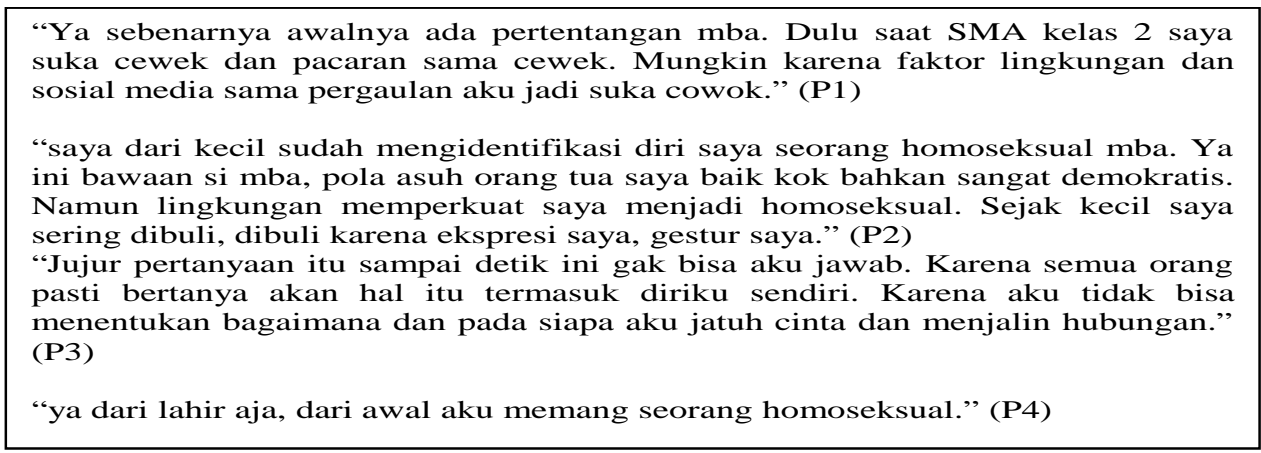

\section{Bagan 3. Pengaruh faktor keturunan terhadap perilaku homoseksual}

"Gak ada deh." (P1)

"gak ada mba." (P2)

"yang unik adalah aku pernah cari tahu. Dari keturunan mamah aku kayaknya pakde atau om aku ada si yang homoseksual. Tapi secara pastinya aku gak bisa melacak.At least yang aku tahu si gak ada ya keturunan yang homoseksual selain aku."(P3)

"gak ada sih mba". (P4)

\section{Bagan 4. Cara orang tua mendidik dari usia 0 sampai 5 tahun}

\footnotetext{
"aku selalu dididik mandiri dari kecil mba. Aku sering melakukan apapun sendiri.Dari kecil udah biasa sendiri sih." (P1)

"ya setahuku sih aku dibesarkan dengan cara yang baik ya. Sama kaya orang tua lainnlah.Mungkin aku emang agak lebih dimanja si kali ya. (P2)

"aku gak inget pasti si. Tapi hal yang aku ingat si aku dekat banget sama papa. Papa suka beliin aku mobil-mobilan, pernah dalam satu kampong Cuma aku yang punya mobil-mobilan gede yang ada baterainya.."(P3)

"ya mungkin sama kaya orang tua lain ya. Wajar-wajar aja, baik sesuai kaidah.Hehehe". (P4)
} 


\section{Bagan 5. Pengalaman yang tidak menyenangkan dengan lawan jenis sebelumnya}

"Gak ada kok. Dulu aku pacaran sama cewek gak ada masalah si. Tapi emang lebih nyaman sama cowok, bisa kayak kakak ade yang klop..” (P1)

"gak ada juga. Justru saya paling dekat dengan lawan jenis, saya suka lendetan di bahunya.Saya juga suka mesra-mesraan dengan lawan jenis saya." (P2)

"jujur si aku belum pernah ngerasain jatuh cinta sama perempuan, kalo pacaran dengan perempuan aku pernah, bahkan aku dicap playboy karena pernah pacaran sama 13 perempuan. Tapi karena aku gak punya ketertarikan sama sekali dengan cewek aku gak pernah ngerasain sakit hati sama cewek."(P3)

"gak ada si, fine-fine aja kok.mungkin lebih nyaman sebagai temen curhat gitu deh". (P4)

\section{Bagan 6. Perilaku Homoseksual}

"Aku tetap berteman kaya orang biasa, gak ada masalah.Tetap ngobrol sama yang lainnya." (P1)

"Saya menjadi diri saya apa adanya.Kami sudah menerima diri kami sebagai seorang homoseksual agar tidak denial. Lalu saya juga melakukan pendekatan sama orang lain. Saya saling memahami dengan

teman-teman saya. Teman-teman saya juga tahu dan menerima saya sebagai seorang homoseksual." (P2)

\section{Bagan 7. Komunikasi Dengan Lawan Jenis}

“Tetap sama kayak orang pada umumnya lah.” (P1)

"Ya tetep baik.Saya kan dekat dengan lawan jenis mba." (P2)

"aku si baik-aja, gak ada masalah. Justru kadang aku merasa jauh lebih nyaman berinteraksi dengan lawan jenis. Karena kadang kalo ngumpul sama temen cowok kadang aku gak nyambung, misalnya bahas cewek malah aku gak nyaman. Kalo sama cewek aku bisa curhat-curhatan, ngomongin cowok hehe.”. (P3)

"ya baik lah. Mereka juga bisa paham kok.Dan mungkin ngerasa nyaman juga kali ya". (P4)

\section{Bagan 8. Perilaku Seksual Partisipan}

“ya baik-baik aja, aku gak pernah mikirin negatifnya. Ya biasa kaya gitu lah.Paling ya hmmm, lewat lubang anus.Tapi tergantung juga si.Tergantung pasangan juga.Aku Cuma sama pacar aku kok, baru 3 bula sama dia. Dia tertutup dan gak ikutan komunitas si." (P1)

"saya lebih ke emosional sama romantik, jadi kaya pasangan hetero si. Suka jalan-jalan bareng.Ya gak saya pungkiri juga secara seksual.Saya ya masih seperti anal oral dan frekeunsinya jarang.lebih suka jalanjalan dan jarang ketemu.Gak ada patokan jadwal untuk berhubungan seksual si.Tergantung mood aja, gak bisa saya maksain pas dia gak pengen, begitu juga sebaliknya. Hehe, saling pengertian aja” (P2)

"ya perilaku seksual sejauh ini aman-aman aja. Selalu pakai kondom.Aku ya anal, oral, patting, kissing, necking ya semuanya, biasa aja. Kita kan selalu ceck setiap 3 bulan, jadi ngerasa aman aja. Aku kan komit sama satu pasangan aja. Aku ngelakuin sesuai kesepakatan aja, kadang di kos, kadang di kontakan dia, kalo bosen ya kadang keluar jalan-jalan”. (P3)

“ya sama kaya temen-temen lain mungkin ya. Ya anal, oral semuanya lah.hehehe." (P4) 


\section{Bagan 9. Perilaku Umum di Dalam dan Luar Komunitas}

"Di dalam komunitas baik-baik aja kok tidak ada kendala.Kalo ada waktu suka jalan-jalan, traveling bareng.Dengan teman di luar komunitas juga gak ada Kendala, biasa aja." (P1)

"ya seperti saya apa adanya. Saya menerima semua impact yang bisa saya terima sebagai seorang homoseksual. Dan saya berperilaku sebagai diri saya apa adanya" (P2)

"aku tidak perneh membedakan perilaku ku di dalam dan di luar komunitas,aku jadi diri sendiri aja". (P3)

"ya sama aja si. Aku berperilaku layaknya orang biasa.Aku gak pernah mikir gimana-gimana. Kita sesama manusia kok" (P4)

\section{Pembahasan}

Hasil jawaban partisipan menunjukkan bahwa pemahaman partisipan tentang homoseksual dengan baik. Partisipan mampu menjelaskan pengertian homoksesual dengan cukup jelas bahkan disertai literatur dan definisi ilmiah. Beberapa diantaranya menggunakan literasi yang baik dalam menjawab pertanyaan tentang apa itu homoksesual. Seperti pada partsipan 1 dan 2, bahkan partisipan 2 mampu menyebutkan jurnal dan panduan ilmiah dalam menyebutkan apa itu homoseksual.

Sebagian besar partisipan menjawab pertanyaan apa itu homoseksual dengan sikap terbuka. Partisipan 1,2, 3 dan 4 menyebutkan definisi homoseksual dengan tegas sesuai dengan apa yang mereka ketahui. Sebagian besar partisipan merupakan mahasiswa dan karyawan yang bekerja di perusahaan. Hal tersebut sesuai dengan teori yang dikemukakan oleh Notoadmodjo (2010), bahwa pengalaman dan tingkat pendidikan berbanding lurus dengan tingkat pengetahuan sesorang.

Penelitian serupa yang dilakukan oleh Isy Royhanati (2016) tentang persepsi kaum gay tentang fenomena LGBT di Kota Semarang menunjukkan bahwa sebagian besar partisipan mampu memberikan jawaban yang tepat tentang apa itu homoseksual. Keterbukaan akan keberadaan mereka ditengah masyarakat dan tingkat pendidikan para partisipan yang tinggi menjadi penyebab partsisipan mampu memberikan definisi yang tepat akan fenomena tersebut.

Hasil wawancara tersebut di atas menunjukkan penyebab partisipan menjadi homoseksual cukup beragam. Ada partisipan yang menyatakan awalnya merupakan seorang heteroseksual dan ada yang sudah merasa menjadi homoseksual sejak lahir. Pernyataan partisipan diperkuat oleh triangulasi sumber bahwa penyebab yang membuat seseorang menjadi homoseksual "Ada banyak hal, diantaranya ialah karena psikodinamika, artinya tergantung pada psikologis dan pengalaman hidupnya. Kemudian memang terjadi secara biologis yakni akibat faktor genetik dan hormonal. 
Ataupun karena adanya pembelajaran dari proses ia bergaul dan lingkungan yang kemudian membentuknya secara kognitif.

Sebagian besar partisipan mengutarakan bahwa dirinya sudah menjadi seorang homoseksual sejak kecil. Partisipan 2, partispan 3 dan partisipan 4 dengan tegas menyatakan dirinya adalah homoseksual sejak lahir. Berbeda halnya dengan partsipan lainnya, partisipan 1 menyebutkan bahwa dirinya awalnya merupakan seorang heteroseksual. Namun selepas SMA menjadi homoseksual akibat lingkungan, pergaulan dan pengaruh media sosial. Khusus untuk partsipan 3 tidak mampu menjabarakan alasan yang menyebabkan dirinya menjadi seorang homoseksual. Sebagian orang tua partisipan mengatakan bahwa penyebab seorang menjadi homoseksual adalah ketentuan dari Tuhan. Pada penelitian ini tidak ditemjukan adanya pengaruh dari polasuh dan faktor keturunan. Dalam teori menjelaskann bahwa adanya komponen genetik yang kuat pada homoseksual. Bahwa homoseksual pria cenderung memiliki saudara homoseksual dari bagian ibunya, dan dengan menelusuri jejak keberadaan gen homoseksual melalui garis keturuan ibu. Pria gay memiliki saudara laki-laki gay daripada saudara laki-laki lesbian, sementara para lesbian memiliki lebih banyak saudara perempuan lesbian daripada saudara lakilaki gay. Penelitian ini juga menemukan bukti bahwa gen gay ada pada kromosom $\mathrm{X}$ tetapi tidak menemukan gen lesbian (Asteria, 2011).

Keterkaitan trauma masa lalu dengan perilaku homoseksual tidak ditemukan, pada partisipan 1 yang awalnya seorang heteroseksual dan pernah menjalin hubungan dengan lawan jenis mengatakan bahwa dihubungannya terdahulu ia tidak mengalami peristiwa yang tidak menyenangkan, namun tetap dirinya merasa lebih nyaman dengan pria. Partisipan 3 mengatakan dirinya pernah menjalin hubungan dengan banyak perempuan, nemun tidak merasakan perasaan cinta dan ketertarikan seksual pada lawan jenis. Ketidaktarikan secara romantis dan seksual adalah hal yang membuat dirinya tidak pernah merasa sakit hati dan kecewa pada lawan jenis yang pernah menjadi pasangannya. Adanya perasaan di masa lalu sejatinya adalah salah satu faktor yangdapat menyebabkan seseorang menjadi homoseksual.

Penelitian yang dilakukan Gesti Lestari (2012) tentang studi fenomenologi homoseksual di Yogyakarta mengungkapkan bahwa sebagian partisipan dalam penelitiannya memiliki trauma percintaan yang membuat mereka takut menjalani hubungan dengan lawan jenis. Trauma dimasa lampau menjadi sebuah determinan yang kuat bagi sesorang dalam perkembangan mental dan psikis seseorang. Pengalaman buruk yang terus membekas pada ingatan seseorang bukan saja 
dapat mengganggu perkembangan mental seseorang, hal tersebut juga dapat merubah kepribadian atau jati diri seseorang. Pengalaman seksual yang menyebabkan trauma baik dari lawan jenis atau bahkan sesama jenis dapat membuat seseorang menjadi seorang homoseksual

Dalam interaksi sosial pelaku homoseksual dengan sesama maupun lawan jenis tidak menunjukkan masalah. Mereka tetap menjalin hubungan dengan baik kepada sesama jenis maupun lawan jenisnya. Hal tersebut sesuai dengan informasi yang diberikan oleh triangulasi sumber yang menyatakan bahwa homoseksual tidak memiliki masalah dalam berkomunikasi dengan sesama maupun lawan jenis. Sebagian dari mereka lebih dekat dengan wanita dan sebagian bahkan bersikap lebih dekat menyerupai wanita yang lebih dikenal dengan gaya ngondek. Sedangkan para orang tua partisipan mengungkapkan bahwa komunikasi homoseksual dengan orang lain sama saja pada orang pada umumnya.

Hasil wawancara tetang perilaku seksual menunjukkan partisipan dengan terbuka memberikan informasi tentang bagaimana perilaku seksual mereka. Partisipan secara terbuka menerangkan bahwa hubungan yang mereka bina dengan pasangan bukan hanya selalu tentang masalah seksual tapi juga tentang keromantisan dan komitmen. Seperti yang dikatakan oleh partisipan 2, 3 dan 4. Secara seksual partsipan melakukan hubungan baik oral maupun anal. Partisipan 1 meungkapkan ia kerap melakukan hubungan secara anal maupun oral sesuai dengan mood ia dan pasangan. Pasrtisipan 3 mengungkapkan bahwa ia bukan hanya melakukan oral dan anal melainkan juga patting, kissing, necking. Partisipan 4 mengungkapkan bahwa dirinya juga melakukan hubungan secara anal. Hasil ini serupa dengan penjelasan yang diberikan oleh triangulasisumber, bahwa homoseksual melakukan hubungan seksual secara anal, oral juga dengan bodycontact. Mereka juga membina hubungan dengan dasar kenyamanan dan keromantisan layaknya pasangan heteroseksual.

Hasil wawancara ini juga serupa dengan penelitian yang dilakukan oleh Gesti Lestari (2012) tentang Fenomena Homoseksual di Yogyakarta, bahwa para partisipan melakukan hubungan seksual secara oral, sentuhan tubuh dan juga anal. Para partisipan juga menggunakan komitmen dalam berhubungan dan ada dasar hubungan saling percaya.

Orang tua partisipan mengatakan bahwa homoseksual melakukan hubungan seks dengan cara anal. Orang tua partisipan sebagian besar memberikan pernyataan dengan kurang nyaman saat membicarakan perilaku seks homoseksual. Mereka mengatakan tidak tahu dengan pasti, namun mereka mengungkapkan biasanya homoseksual melakukan hubungan seks lewat dubur. 
Dan tentang bagimana perasaan para partisipan terhadap perilakunya tersebut, hampir seluruh partisipan mengungkapkan perasaaanya biasa saja, malah cenderung senang dan hanya 1 partisipan yang merasa cemas atau was-was. Partisipan measa aman karena menggunakan alat pengaman dalam aktiftas seksualnya.

\section{Kesimpulan}

Studi fenomologi tentang perilaku homoseksual ini menyimpulkan bahwa partisipan sangat memahami tentang perilaku seksual yang menyimpang yang dialaminya, dan penelusuran faktorfaktor yang mempengaruhi tidak diketemukan adanya faktor keturunan dan lebih banyak karena faktor lingkungan, pergaulan sosial. Perilaku homoseksual juga tidak mempengaruhi interaksi sosial antara sesama jenis maupun dengan lawan jenisnya. Faktor pola asuh juga tidak diketemukan, frata-rat mereka mendapat polasuh yang baik dari orangtuanya. Perilaku seksual yang dilakukan beragam dari mulai patting, kissing, necking sampai melakukan oral dan anal. Partisipan juga mengungkapkan perasaannya tentang adanya kecemasan terhadap dampak perilaku seksual yang dilakukan, sehingga mereka mengantisipasinya dengan menggunakan pengaman sepeerti kondom. Studi ini telah mendapatkan gambaran tentang pemahaman, sikap dan perilaku homoseksual di kota Semarang.

\section{Saran}

Penelitian selanjutnya lebih menggali tentang nilai dan keyakinan pada perilaku homoseksual serta dampak psikologis dan fisiolgisnya. Pendidikan kesehatan perlu diberikan kepada para homoseksual tentunya berkaitan dengan damapk kesehatan dan dampak psikologisnya.

\section{Daftar Pustaka}

Adesla, V. (2009). Definisi dan proses homoseksual [Online] Tersedia: http://www.epsikologi.com/epsi/klinis_detail.asp?id=551[13 oktober 2011].

Afifuddin dan Saebani, B.A. (2010). Metodologi. Penelitian kualitatif. Bandung: Pustaka Setia. Anonim. (2012). Mengenal Orientasi Seksual. www.mitrawacana.or.id Diakses pada tanggal 9 Maret 2016.

Asteria. (2011). Ancaman Perilaku homoseksual [online] Tersedia: http://www.inilah.com/read/detail/15225/ancaman-perilaku-homoseksual [29Desember 2011].

Colin Spencer, (2010). Sejarah homoseksualitas, kreasi wacana. Yogyakarta.

Dewi. (2015). Orientasi seksual penyimpangan karena faktor eksternal. Replublika. Diunduh dari http://mrepublika.co.id. 
Dwilaksono,W. (2014). Kontrol Diri Dan Perilaku Seksual Primisif Pada Gay. Diakses pada 16 juli 2016, dari file:///C:Users/acer/downloads/kontrol\%20Diri\%20dan\%20perilaku\%seksual\%20permi sif\%20pada\%gay\%20(2013)\%2092).pdf.

Reksodirdjo, W. (2011). Homoseksualitas di Indonesia: Antara Kenyataan Dan Hipokritas.

Sunaryo. (2011). Metodologi Penelitian Kualitatif dalam Kesehatan. Yogyakarta : Nuha Medika.

Tahmindjis, P. (2014). Sexuality and Human Rights : A Global Overview. London: Routledge. UNDP. (2014). Laporan LGBT Nasional Indonesia - Hidup sebagai LGBT di Asia. UNDP Asia Pasifik. 